\title{
Thermal characteristics of spring steels used in railway bogies
}

\author{
Velaphi Jeffrey Matjeke ${ }^{1}$ Josias Willem Van Der Merwe ${ }^{1} \cdot$ Goodness Mukwevho ${ }^{2} \cdot$ Maje Jacob Phasha $^{2}$
}

Received: 17 August 2019 / Accepted: 20 October 2019 / Published online: 5 November 2019

(c) Springer Nature Switzerland AG 2019

\begin{abstract}
During the heat treatment of springs for railway bogies, phase transformations and oxidation occur and it is important to know transformation temperatures and oxidation rates to optimise the process. Oxidation and decarburisation can adversely affect the surface properties of steel when not limited to the bare minimum. The oxidation rates and materialspecific phase transformation of the spring steels were evaluated by means of differential scanning calorimetry. Three spring steels with known mass were heated and cooled. The change in the corresponding heat flow was evaluated. The materials were also subjected to a regular spring steel heat treatment process in order to determine the relationship between oxidation rate and decarburisation. This allowed for the observation of phase transition and oxidation rate for each steel. The results of these investigations showed that there is a nonlinear relationship between oxidation and decarburisation. The three materials analysed showed distinct properties; therefore, understanding of the material characteristics is important. Material A showed a high oxidation rate with decreased decarburisation, whereas material B showed less oxidation and higher decarburisation due to higher silicon contents.
\end{abstract}

Keywords Railway · Springs · Heat treatment · Oxidation

\section{Introduction}

Bogie springs are manufactured from high strength steels that have to be heat-treated properly, in order to produce functional springs properties [1]. During the heat-treating processes used with spring steel, phase transformations occur that change the crystalline structure and affect the mechanical properties of the steel [2]. It is important to know the exact transformation temperatures, in order to determine the maximum heat treatment efficiency and the effect thereof on the structure of the specific spring steel. This will assist with optimisation and increasing efficiency during the heat treatment process. The heat treatment process entails phase development when heated and cooled at determined rates [3]. In order for the heat treatment process to be optimised, the precise parameters have to be determined [4]. Generally, the heat treatment cycle involved in the spring manufacturing process has the following sequence:

- Initially, steel rods are heated in a controlled furnace to approximately $850^{\circ} \mathrm{C}$.

- This is followed by quench hardening to produce a martensitic structure [5].

- This is followed by a tempering heat treatment, at approximately $430 \pm 20^{\circ} \mathrm{C}$ for $3 \mathrm{~h}$, to complete the heat treatment cycle.

However, the thermal characteristic of steel varies with compositional variation. As a result, the efficiency of heat treatment can be impacted. Furthermore, during the heat treatment process, the steel surface oxidises and forms scales when exposed to air [6]. In addition, the surface decarburises during the heat treatment process. These

$\triangle$ Velaphi Jeffrey Matjeke, Velaphi.matjeke@gmail.com | 'School of Chemical and Metallurgical Engineering, University of the Witwatersrand (Wits), Private Bag X3, Johannesburg 2050, South Africa. ${ }^{2}$ Transnet Engineering, Research and Development, Private Bag X528, Pretoria 01272, South Africa. 
two processes deteriorate the spring surface properties, which adversely affects the fatigue properties [7]. It is important to understand this behaviour for each grade of steel, because it can deteriorate the mechanical properties of the springs. This study will focus on the thermogravimetric characteristics of spring steels and the surface properties of the steels during heat treatment, oxidation and decarburization. A large body of work has been done on thermogravimetric analysis of various metals; however, not much has been carried out for spring steels. The oxidation and decarburisation of steels have been extensively investigated [8-11]. They have investigated various steel chemistries and conditions; however, the specific condition and chemistry of spring steels have not been investigated, and there is limited information on the oxidation rates of specific spring steels. Shi et al. [12] evaluated the sensitivity of various spring steels to decarburisation and oxidation, but did not show the relationship between them. In pursuit to understand how decarburisation of steel can be reduced, Zorc et al. [11] conducted a study of oxidation and decarburisation of non-alloyed C45 steel at various temperatures. In the current study, three alloyed spring steels were heat-treated and evaluated against decarburisation and oxidation. The transformation characteristics of these steels were also determined in order to understand the behaviour of material when subjected to heat treatment. Generally, continuous cooling temperature (CCT) curves only provide limited information regarding the heat treatment process and CCT curve of steels is unique. Thermal analysis techniques are generally used to determine how material composition changes heat flow. Phase transformation takes place at a specific temperature and can be determined when alloyed steels are subjected to heating and cooling [13]. An understanding of phase transformation information must be developed, in order to ensure efficient metallurgical operation. Usually, the underlying reaction and transformation kinetics of steels are studied with differential scanning calorimetry (DSC) [14]. This thermo-analytical technique (DSC) was employed to investigate the behaviour of the three spring steels. Calorimetry is one of the most accurate and suitable methods for analysing materials by determining their heat flow rate as a function of temperature and time. Calorimetry bases its measurements on endothermic and exothermic processes [15]. Phase transformation that occurs during the heat treatment process influences the metallurgical and mechanical properties of the steel dramatically [16]. The austenite transformation plays a significant role in terms of mechanical properties, followed by the chemical composition and the cooling rate [17]. According to the binary $\mathrm{Fe} 3 \mathrm{C}$ phase diagram presented in Fig. 1, the start of austenite transformation during heating begins at $723^{\circ} \mathrm{C}(\mathrm{Ac} 1)$. Complete austenite transformation

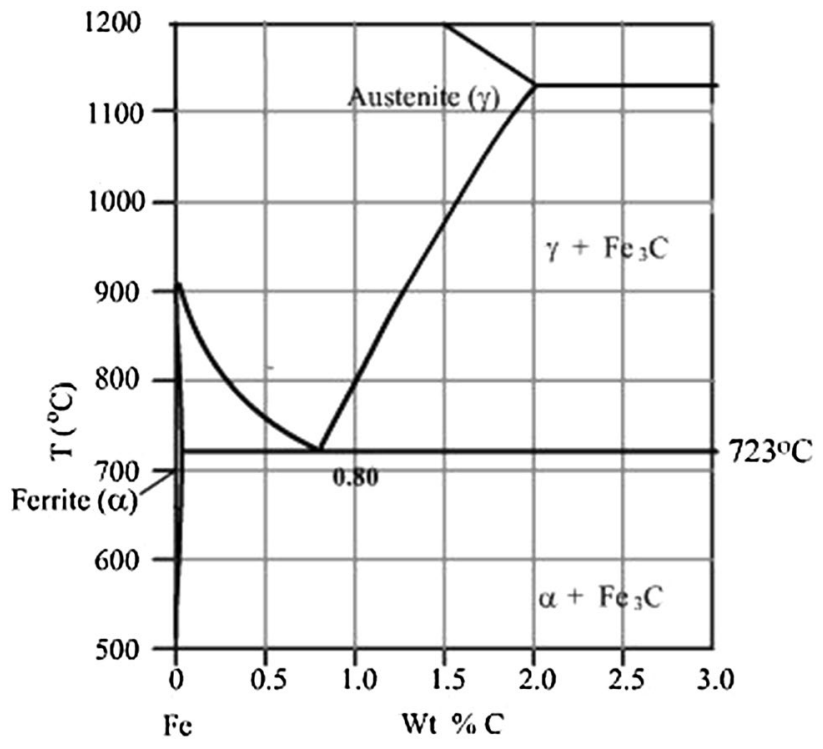

Fig. 1 Fe-Fe3C diagram [18]

is achieved when the Ac3 transformation line is achieved. The martensite structure is achieved when rapidly cooling the steel from the austenite range. Austenite $((x))$ and ferrite ( $\alpha$ ) phases have FCC and BCC crystal structures, respectively, whilst martensite has a BCT structure. The aim of this study was to determine the exact transformation temperatures of the three spring steels, as well as their high temperature oxidation rates. The first part of the study focused on DSC measurements, whilst the second part focused on experimental heat treatment results, so as to validate the high temperature oxidation rate. In the investigation described in this work, a fair amount of attention was given to rates of oxidation and the decarburisation of steel in air at atmospheric pressure.

\section{Materials and experimental procedure}

Three spring steel materials were selected for heat treatment optimisation. This section focuses on thermal analysis and heat treatment of the three different spring steels. The three spring steels were marked material A, B and C for identification purposes. The chemical composition of the steels was determined using an ultraviolet chemical spectrometer.

\subsection{Differential scanning calorimetry}

An SDT Q600 DSC equipped with a DSC-TGA module was used for experimental thermal analysis. The materials were ground to produce fine particles, and the samples were initially weighed with the instrument before the analysis 
began. The chamber temperature was increased to $860^{\circ} \mathrm{C}$ at $120^{\circ} \mathrm{C} / \mathrm{min}$, from room temperature, and held for $2 \mathrm{~min}$ before cooling at the same rate. All three materials experienced the same heating and cooling cycle under atmospheric conditions. Furthermore, the oxidation rates were determined by holding the samples isothermally, after they were heated to $860^{\circ} \mathrm{C}$, whilst purging with argon gas. The samples were then isothermally held at $860^{\circ} \mathrm{C}$ for 60 min under atmospheric conditions.

\subsection{JMatPro}

JMatPro software was used to predict the thermal properties of the materials. Continuous cooling temperature (CCT) curves were plotted using the software. The martensite start temperature was estimated using JMatPro practical software and compared with the Andrews equation 1.

$$
\begin{aligned}
M_{\mathrm{s}}\left({ }^{\circ} \mathrm{C}\right) & =539-423(\% \mathrm{C})-30.4(\% \mathrm{Mn})-17.7(\% \mathrm{Ni}) \\
& -12.1(\% \mathrm{Cr})-7.5(\% \mathrm{Mo})
\end{aligned}
$$

\subsection{Heat treatment}

The steels were subjected to the heat treatment process in a controlled furnace in order to evaluate decarburisation and oxidation behaviour of the material. The heat treatment entailed solution treating at $860^{\circ} \mathrm{C}$ for an hour and subsequently quenching in oil. The samples were tempered at $450^{\circ} \mathrm{C}$ for $3 \mathrm{~h}$. Before heat treatment, the three rods were machined to a depth of $1 \mathrm{~mm}$, in order to remove any possible decarburised surface layer. Transverse sections were polished to $1 \mu \mathrm{m}$ surface finish and etched with picric acid for purposes of microstructural analysis.

\section{Results}

\subsection{Chemical analysis}

The chemical composition results are shown in Table 1 . The chemistries of materials $A, B$ and $C$ aligned with steel grades are $55 \mathrm{Cr} 3,54 \mathrm{SiCr} 6$ and $52 \mathrm{CrMoV} 4$, respectively. Material B contained a significant amount of silicon, compared with 0.32 and $0.28 \%$ observed on material $A$ and $C$, respectively. However, material $C$ contained a significant percentage of chromium, vanadium and molybdenum compared to material $\mathrm{A}$ and $\mathrm{B}$.

\subsection{Thermal analysis}

The DSC measurements shown in Fig. 2 show three curves with an endothermic and exothermic peak, which represent the eutectoid temperatures of the three samples. The heating and cooling peak information is summarised in

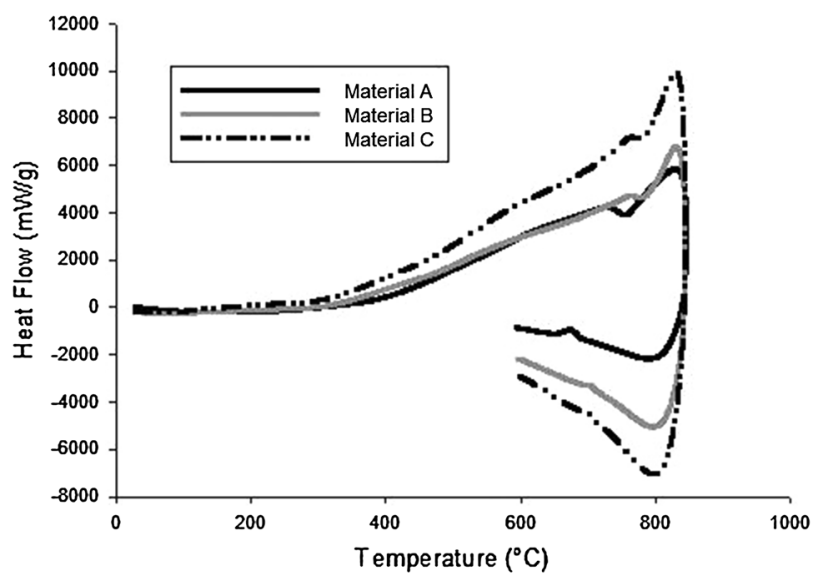

Fig. 2 Heat flow versus temperature plots for material A, B and C
Table 1 Chemical composition

\begin{tabular}{|c|c|c|c|c|c|c|}
\hline \multirow[t]{2}{*}{ Identity/element } & \multicolumn{3}{|l|}{ Test sample } & \multicolumn{3}{|c|}{ BS EN 10089 Specification } \\
\hline & Material A & Material B & Material C & $55 \mathrm{Cr} 3$ & $54 \mathrm{SiCr} 6$ & $52 \mathrm{CrMoV} 4$ \\
\hline \%Carbon & 0.58 & 0.56 & 0.55 & 0.520 .59 & 0.510 .59 & 0.480 .56 \\
\hline \%Silicon & 0.32 & 1.33 & 0.28 & $0.40 \max$ & 1.201 .60 & $0.40 \max$ \\
\hline \%Manganese & 0.92 & 0.71 & 0.92 & 0.701 .00 & 0.500 .80 & 0.701 .10 \\
\hline \%Phosphorus & 0.013 & 0.014 & $0.0120 .025 \max$ & $0.025 \max$ & $0.25 \max$ & \\
\hline \%Sulphur & 0.004 & 0.002 & 0.007 & $0.025 \max$ & $0.025 \max$ & $0.25 \max$ \\
\hline \%Chromium & 0.79 & 0.75 & 1.05 & 0.701 .00 & 0.500 .80 & 0.901 .20 \\
\hline$\%$ Nickel & 0.06 & 0.01 & 0.01 & * & * & * \\
\hline \%Copper & 0.10 & 0.01 & 0.01 & * & * & * \\
\hline \%olybdenum & 0.01 & 0.00 & 0.19 & * & * & 0.150 .30 \\
\hline \%Vanadium & 0.01 & 0.06 & 0.11 & $*$ & * & 0.100 .20 \\
\hline
\end{tabular}
of the spring steels in wt $\%$
*Not specified 
Table 2 Endothermic and exothermic reaction details

\begin{tabular}{|c|c|c|c|c|c|c|}
\hline \multirow[t]{2}{*}{ Sample } & \multicolumn{3}{|l|}{ Heating } & \multicolumn{3}{|l|}{ Cooling } \\
\hline & Time (min) & $\begin{array}{l}\text { Eutectoid tem- } \\
\text { perature }\left({ }^{\circ} \mathrm{C}\right)\end{array}$ & $\begin{array}{l}\text { Heat flow } \\
(\mathrm{mW} / \mathrm{g})\end{array}$ & Time (min) & $\begin{array}{l}\text { Eutectoid tem- } \\
\text { perature }\left({ }^{\circ} \mathrm{C}\right)\end{array}$ & $\begin{array}{l}\text { Heat } \\
\text { Flow } \\
(\mathrm{mW} / \mathrm{g})\end{array}$ \\
\hline Material A & 6.18 & 729.58 & 4246 & 11.98 & 689.23 & 1297 \\
\hline Material B & 7.70 & 761.82 & 4702 & 12.65 & 713.93 & 3566 \\
\hline Material C & 7.76 & 766.08 & 7201 & 12.81 & 709.67 & 4769 \\
\hline
\end{tabular}

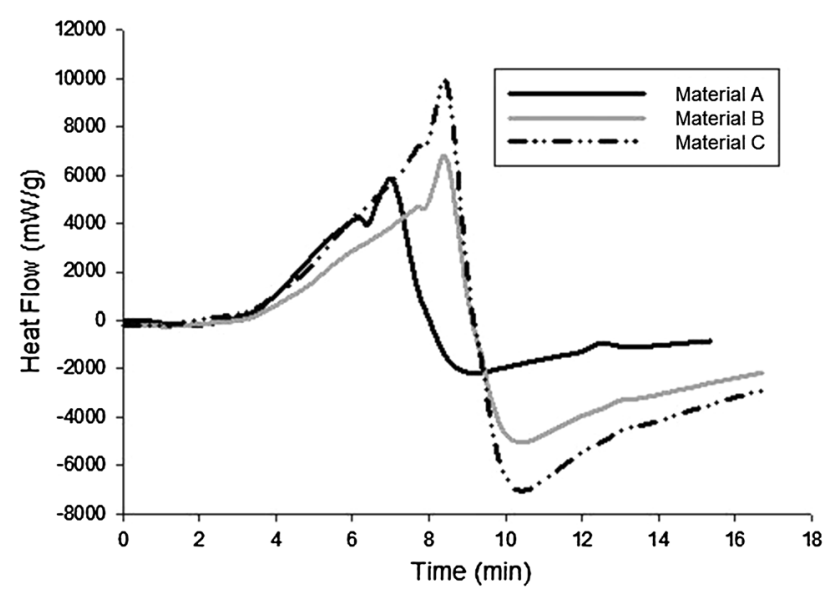

Fig. 3 Heat flow versus time plot of the three steels

Table 2. The materials showed distinct thermal properties, with material $A$ requiring lower heat flow than materials $B$ and $C$. In addition, the eutectoid temperature of material A was lower compared to material B and C.

Figure 3 presents the required heat flow over time. The trends of the graphs show that material $C$ requires significantly higher heat flow to achieve the eutectoid temperature at approximately the same time as material A and B. Figure 4 shows the behaviour of the three materials during heating, whilst purging with argon, followed by isothermal treatment for $60 \mathrm{~min}$ in the atmosphere. The graph for material $C$ fell between that for material $A$ and $B$. Table 3 presents the sample weight before analysis and the weight after heating and exposure to the atmosphere. Figure 5 shows the weight gain due to heating and exposure to the atmosphere. The oxidation rate was determined by plotting the gradient once the graph on Fig. 6 had stabilized. Material A showed a higher oxidation rate, whilst material $B$ showed itself to be more resistant to oxidation. The oxidation rates were calculated when the graph stabilised. Despite the slightly smaller weight, the oxidation rate of material $C$ is less than that of $A$, but higher than $B$.

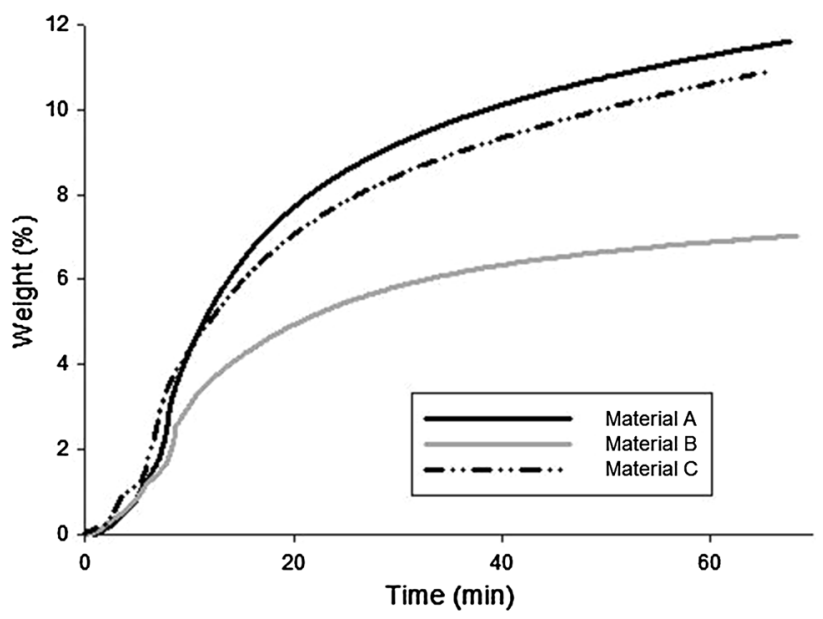

Fig. 4 Oxidation in weight percentage versus time of the three steels

Table 3 Oxidation characteristics at $860^{\circ} \mathrm{C}$

\begin{tabular}{llccc}
\hline Identity & $\begin{array}{l}\text { Initial } \\
\text { weight } \\
(\mu \mathrm{g})\end{array}$ & Final weight $(\mu \mathrm{g})$ & Oxidation (\%) & $\begin{array}{l}\text { Oxida- } \\
\text { tion rate } \\
(\mu \mathrm{g} / \mathrm{min})\end{array}$ \\
\hline Material A & 9178 & 10,384 & 11.6 & 131,587 \\
Material B & 9393 & 9794 & 4.1 & 18,054 \\
Material C & 6465 & 6954 & 7.0 & 28,154 \\
\hline
\end{tabular}

Figure 7 shows the CCTs for the three materials that were determined using JmatPro software. The martensite start temperature established from the CCT curves and those determined from Andrews equation are summarised in Table 4. While the martensite start temperature for material $A$ and $C$ (determined using JmatPro software and Andrews equation) was comparable, the results for material $B$ were inconsistent. It is worth noting that Andrews equation does not take into account the amount of silicon in the steel, which is significantly higher in material B. 


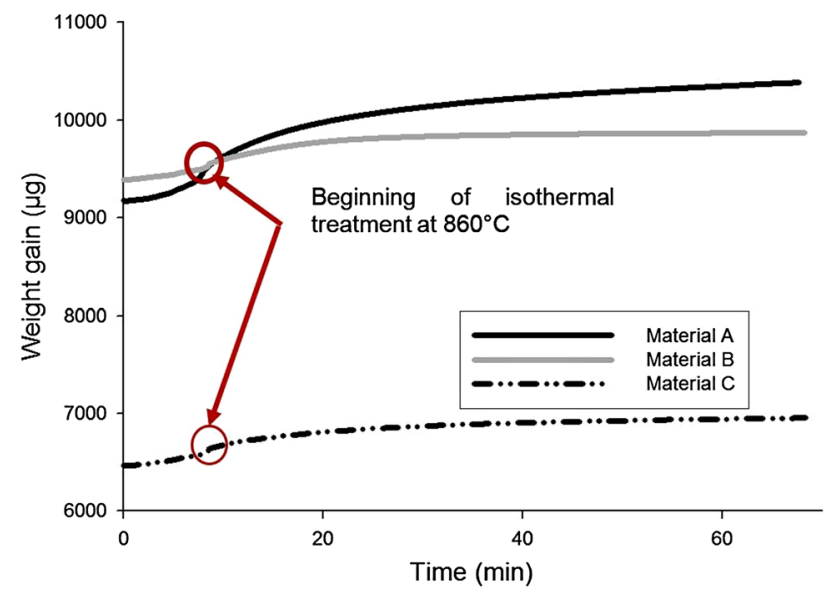

Fig. 5 Oxidation exposure at $860^{\circ} \mathrm{C}$ of the three steels

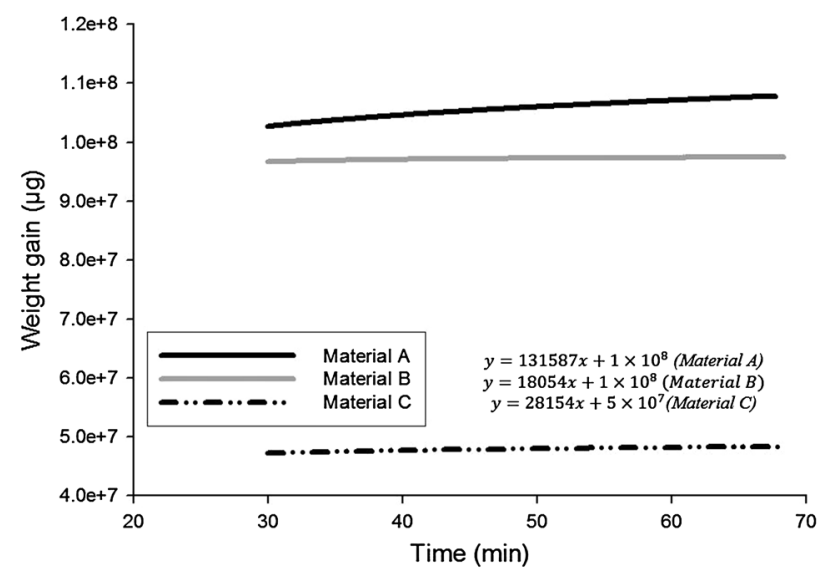

Fig. 6 Oxidation rate at $860^{\circ} \mathrm{C}$ of the three materials

\subsection{Metallographic examination}

The microstructures of the heat-treated samples are shown in Fig. 8. The general microstructure of the three steels was that of tempered martensite with a degree of decarburisation at the edges. Decarburisation occurred on all three samples, but the most occurred with sample B. However, Samples $A$ and $C$ showed a similar microstructure, which is indicative of a lower extent of decarburisation.

\section{Discussion}

Heat treatment optimisation of various steels requires precise knowledge of the parameters and how they influence the behaviour of the material during the heating and cooling processes. The DSC curves of the materials heated to $860^{\circ} \mathrm{C}$ showed high temperature endothermic peaks during heating and exothermic peaks during cooling in air. The achieved peaks for the different steels were measured at different temperatures. The graphs show that material A required 4606 $\mathrm{mW} / \mathrm{g}$ heat flow to reach the eutectoid temperature, compared to $5679 \mathrm{~mW} / \mathrm{g}$ and $7200 \mathrm{~mW} / \mathrm{g}$ of materials $B$ and $C$, respectively. Therefore, the heat treatment process of the three materials had to be varied according to their specific heat capacity. This will also influence the amount of time the materials spend within the furnace. With the cooling segment at $120^{\circ} \mathrm{C} / \mathrm{min}$, the eutectoid temperature of each steel was found to be lower than the heating eutectoid temperature. The low temperature phase transformation peaks were predicted using the CCT diagrams and Andrews equation. The martensite start temperatures (generated from JmatPro and Andrews equation) were comparable to each other, with the exception of material $B$, which contained a significant silicon content. This behaviour of material $B$ is attributed to the fact that Andrews equation does not take into account the amount of silicon. It is well known that the amount of carbon influences the mechanical properties significantly; however, silicon can substantially influence hardenability. Carbon reduces iron oxide to form carbon monoxide and iron, thus causing decarburisation [19]. A stable oxide scale that forms on the surface hinders the progression of decarburisation [6]. The addition of aluminium and silicon in steel retards oxidation by forming aluminium and silicon-rich scales that prevent the diffusion of iron ions. Silicon readily oxidises to form silicon oxides at a high temperature [20]. Due to the inadequate cooling capability of the DSC instrument used, rapid quenching could not be carried out; however, phase transformation from austenite to martensite was predicted using JmatPro and Andrews equation. The established martensite start temperature will aid in determining the critical cooling rate, and consequently in selecting an appropriate quenching media. Another significant observation made when conducting thermal analysis was the determination of the oxidation rate for each type of steel. Calorimetry analysis indicated a higher oxidation rate for material $A$, followed by $C$, then $B$. The microstructure of sample $B$ displayed severe decarburisation in comparison with sample $A$ and sample $C$. This was found after exposing the samples to $860^{\circ} \mathrm{C}$ for an hour, followed by tempering at $450^{\circ} \mathrm{C}$ for $3 \mathrm{~h}$. Material $\mathrm{B}$ had a significantly higher 


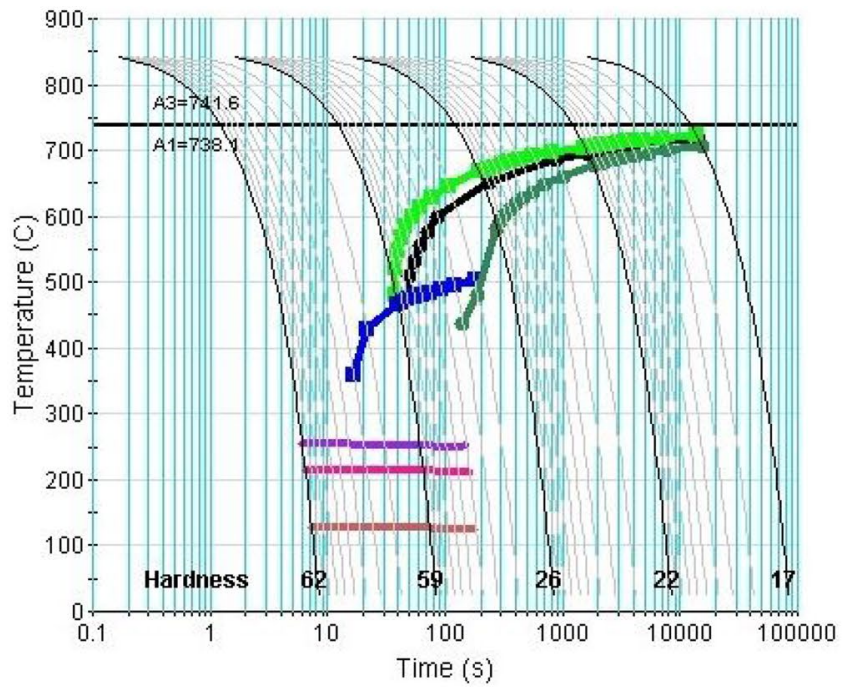

(a) Material A

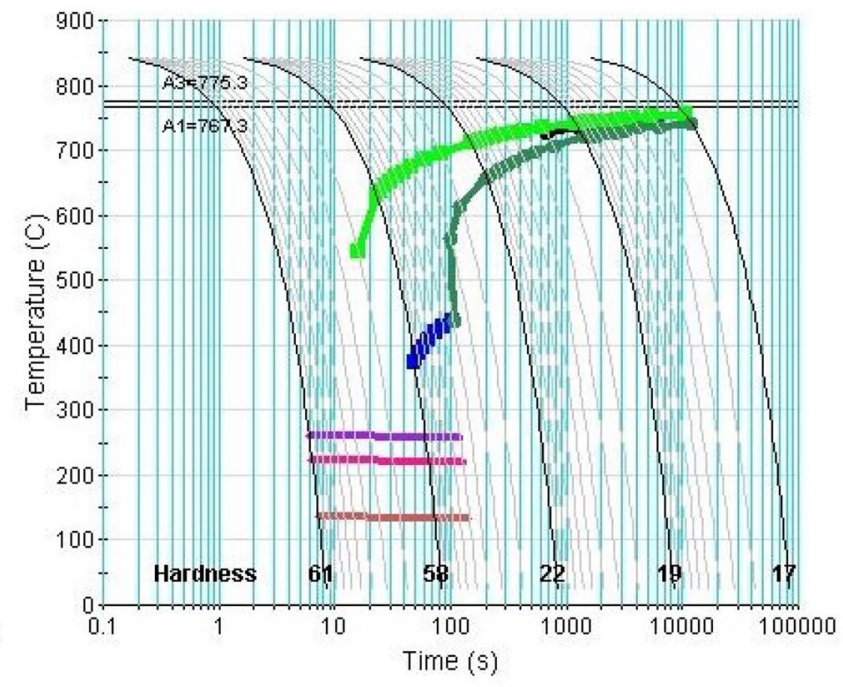

(b) Material B

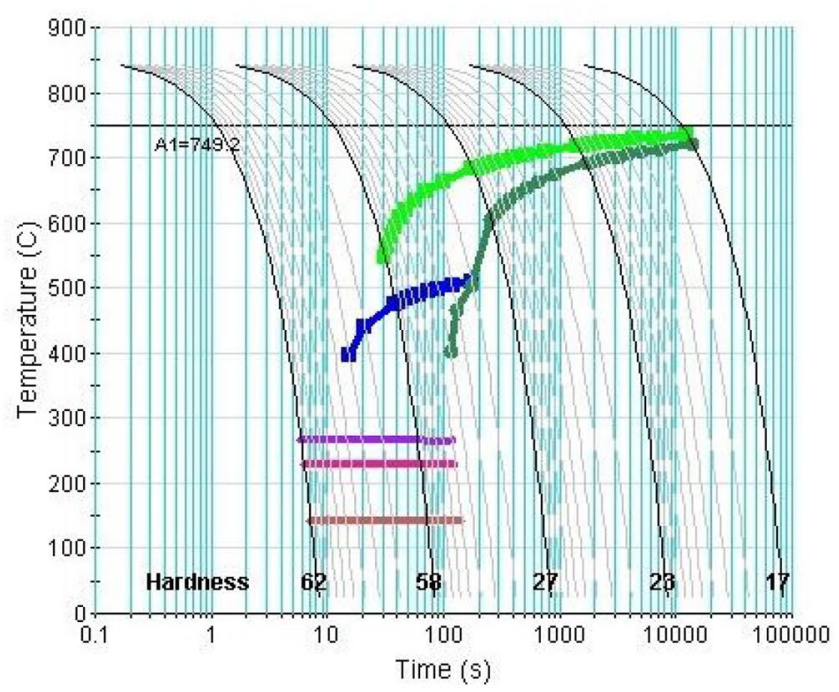

(c) Material C

Fig. 7 Continuous cooling curves

Table 4 Martensite start temperature predictions

Martensite start Material $\mathrm{A}\left({ }^{\circ} \mathrm{C}\right)$ Material $\mathrm{B}\left({ }^{\circ} \mathrm{C}\right)$ Material $\mathrm{C}\left({ }^{\circ} \mathrm{C}\right)$ temperature pre-

diction

\begin{tabular}{llll}
\hline Andrews equation & 254.9 & 271.3 & 264.1 \\
JmatPro estimation & 253.3 & 260.1 & 265.6 \\
\hline
\end{tabular}

silicon level compared to materials A and C. Material C and $A$ showed less decarburisation, which is attributed to protection offered by the thick oxidation scale. The observed behaviour is similar to that reported by Liu et al. [8]. 


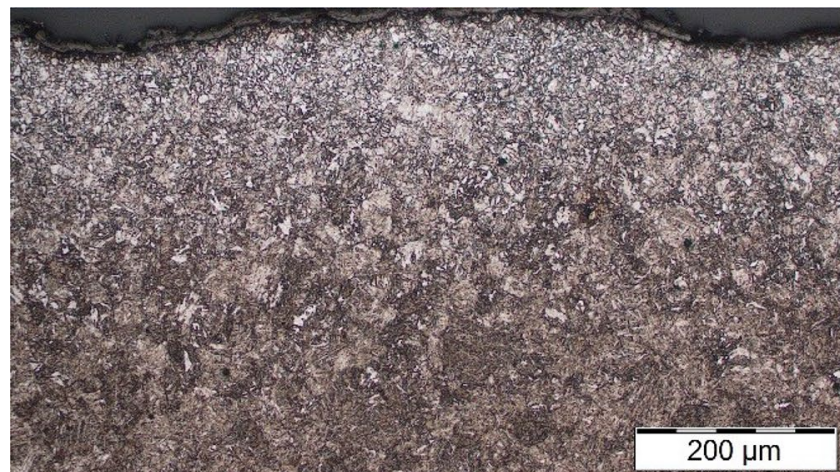

(a) Material A

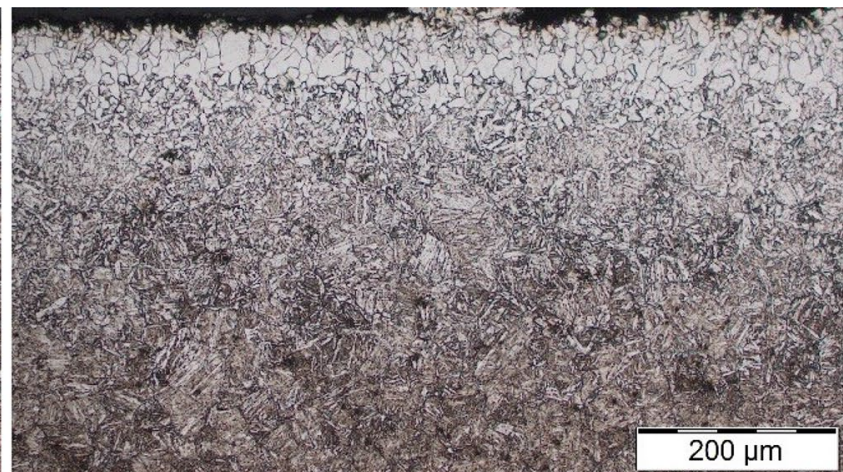

(b) Material B

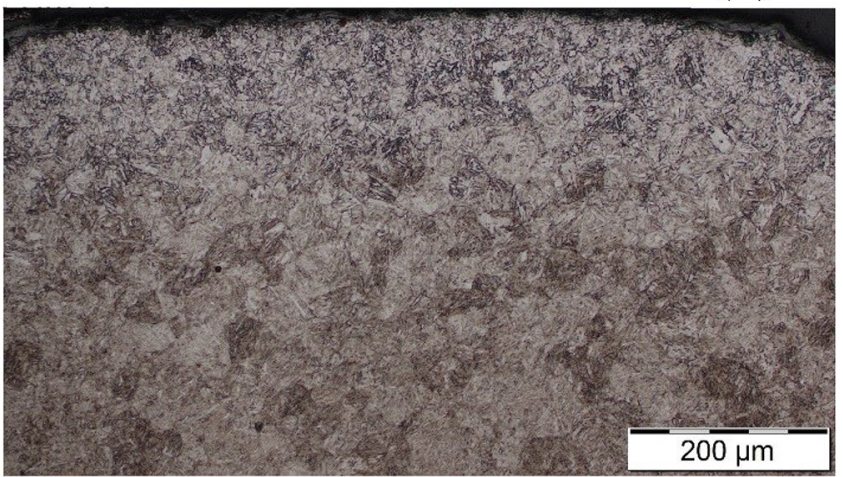

(c) Material C

Fig. 8 Microstructures showing decarburisation

\section{Conclusion}

Thermogravimetric can assist in effectively formulating the heat treatment process by establishing the actual transition temperature and the time required to achieve an interstitial solid solution. This is particularly important because of the heat treatment efficiency and optimisation elements. The calorimetry results showed that the three materials have distinct phase transformation properties. On the other hand, oxidation and decarburization is undesirable because it can degrade the surface properties. Spring steel selection must be accompanied by an understanding of the oxidation/ carburisation rate. Although oxidation may hinder decarburisation, the heat treatment and calorimetry revealed that the relationship between the oxidation rate and decarburisation is not linear. Decreased decarburisation on material $A$ is attributed to high oxidation scale. Material B showed less oxidation and high decarburisation due to significant of silicon content. As a result, it can be concluded that oxidation and decarburisation counteract one another.

\section{Compliance with ethical standards}

Conflict of interest The authors declare that they have no conflict of interest in terms of this study.

\section{References}

1. Liu SY, LLiu DY, Liu SC (2010) Effect of heat treatment on fatigue resistance of spring steel $60 \mathrm{Si} 2 \mathrm{Cr}$. Met Sci Heat Treat Engl Tr 52:57-60

2. Meigui O, Chunlin Y, Jie Z et al (2010) Influence of $\mathrm{Cr}$ content and QPT process on the microstructure and properties of cold-coiled spring steel. J Alloys Compd 697:43-54

3. Barbacki A, Mikoajski E (1998) Optimization of heat treatment conditions for maximum toughness of high strength silicon steel. J Mater Process Technol 78:18-23

4. Matjeke VJ, Mukwevho G, Maleka A et al (2018) Effect of heat treatment on strength and ductility of $52 \mathrm{CrMoV} 4$ spring. https ://doi.org/10.1088/1757-899X/430/1/012044

5. Zhang C, Zhou L, Liu Y (2013) Heredity in the microstructure and mechanical properties of hot-rolled spring steel wire $60 \mathrm{Si} 2 \mathrm{MnA}$ during heat treatment process. J Mater Sci Technol 29:82-88 
6. Chang Y-N, Wei F-I (1989) Review high temperature oxidation of low alloy steels. J Mater Sci 24:14-22

7. Ganesh P, Sundar R, Kumar $\mathrm{H}$ et al (2012) Studies on laser peening of spring steel for automotive applications. Opt Lasers Eng 50:678-86

8. Liu Y, Zhang W, Tong Q, Wang L (2014) Effects of temperature and oxidation and oxygen concentration on the characteristics of decarburisation of $55 \mathrm{SiCr}$ spring steel. ISIJ Int. https:// doi.org/10.2355/isijinternational.51.1920

9. Gutierres-Platas JL, Artigas A, Monsalve A, Garcia NA et al (2018) High temperature oxidation and pickling behavior of HSLA steels. Oxid Met. https://doi.org/10.1007/s1108 5-017-9832-3

10. Zhao F, Zhang CL, Liu YZ (2016) Ferrite decarburisation of high silicon spring steel in three temperature ranges. Arch Metall Mater. https://doi.org/10.1515/amm-2016-0252

11. Zorc M, Nagode A, Burja J, Kosec B, Zorc B (2018) Surface decarburisation of the hypo-eutectoid carbon steel C45 during annealing in steady air at temperatures T > A_c1. Metals. https://doi.org/10.3390/met8060425

12. Shi X-B, Zhao L-Y, Wang W et al (2013) Decarburization sensitivities of several spring steels used for high-speed trains. Mater Heat Treat 34:47-52

13. Klannik G, Medved J, Nagode A et al (2014) Influence of Mn on the solidification of Fe-Si-Al alloy for non-oriented electrical steel. J Therm Anal Calorim 116:295-302
14. Petrovic DS, Pirnat M, Klancnik G et al (2012) The effect of cooling rate on the solidification and microstructure evolution in duplex stainless steel a DSC study. J Therm Anal Calorim 109:1185-91

15. Mukherjee I, Rosolen M (2013) Thermal transitions of gelatin evaluated using DSC sample pans of various seal integrities. J Therm Anal Calorim 114:1161-6

16. Guerra-Fuentes L, Deaquino Lara R, Hernandez-Rodriguez MAL et al (2016) Thermal stability and phase transformations of a FV535 steel. J Therm Anal Calorim 123:27-33

17. Goji M, Sueska M, Raji M (2004) Thermal analysis of low alloy Cr-Mo steel. J Therm Anal 75:947-56

18. http://www-g.eng.cam.ac.uk/mmg/teaching/typd/addenda/ eutectoidreaction 1.html. Cambridge University, 2018

19. Chen RY, Yuen WYD (2003) Review of the high-temperature oxidation of iron and carbon steels in air or oxygen. Oxid Met 59:433-68

20. Ahmad Z (2012) Effect of alloying elements on high-temperature oxidation behaviour of Fe-Si alloys. Hokkaido university, Japan (Dissertation)

Publisher's Note Springer Nature remains neutral with regard to jurisdictional claims in published maps and institutional affiliations. 